\title{
CARACTERIZAÇÃo do ESTÁdio de MATURAÇÃo dO PAPAIA 'GOLDEN' EM FUNÇÃO DA COR ${ }^{1}$
}

\author{
MAYRON AUGUSTO BORGES DE OLIVEIRA², ROMEU VIANNI ${ }^{3}$, GELSON DE SOUZA ${ }^{4}$, \\ THIAGO MOREIRA DE REZENDE ARAÚJO ${ }^{5}$
}

\begin{abstract}
RESUMO - A mudança de cor da casca é uma das variáveis físicas mais utilizadas para avaliar os estádios de maturação de frutas. O mamão apresenta a característica de mudança gradual da cor da casca de verde para amarela. Essa mudança gradual e de maneira desuniforme dificulta a utilização de escalas nominais que estão sujeitas à interpretação e fadiga do observador. Neste trabalho, foram realizadas leituras no papaia 'Golden' tipo exportação. Neste trabalho, foram realizadas leituras dos parâmetros $L, a, b$ e refletância da casca em 100 frutos para os estádios de maturação 2; 3; 4 e 5. Os resultados obtidos indicaram que os parâmetros de Hunter $a$ e $b$ e refletância na casca na região do amarelo e alaranjado são promissoras como medidas físicas objetivas para avaliar os estádios de maturação do papaia 'Golden'.
\end{abstract}

Termos para indexação: Carica papaya L., cor da casca, refletância.

\section{CHARACTERIZATION OF MATURATION STAGE OF 'GOLDEN' PAPAYA IN RELATED COLOR}

\begin{abstract}
The color changes of the peel is one of the physicals parameters most utilized to evaluate the ripening stage of the fruits. The papaya present a characteristic to changing a peel color, from green to yellow. This gradual change accomplished by a not uniform way creates difficulties for the utilization of nominal scale, that are subjected to the interpretation and tiredness to the observant. In this work were made reading in the papaya variety 'Golden' type exportation. In this study, the reading of the parameter $\mathrm{L}, a, b$ and reflectance were made in the peel of 100 fruits for each maturation stage 2, 3, 4 and 5. The results obtaineds indicated that Hunter parameter $a$ and $b$ and the peel reflectance in yellow-orange region are promising as objective physical measures to evaluate the maturation stage of 'Golden' papaya fruits.
\end{abstract}

Index terms: Carica papaya L., color of peel, reflectance.

Os estádios de maturação, o ponto de colheita e de consumo em diversas frutas são definidos pela cor da casca (Kays, 1991). O mamão tem por característica a mudança gradual e desuniforme na cor da casca de verde para amarela, formando inicialmente estrias amarelas partindo da região estilar para a inserção peduncular do fruto.

$\mathrm{Na}$ caracterização da cor da casca do papaia, são muito utilizadas escalas visuais subjetivas (Vieira, et al., 2000). No entanto, esse tipo de escala dificulta a reprodução de resultados entre os observadores devido à interpretação subjetiva e tênue limite entre os estádios de maturação.

$\mathrm{Na}$ casa de embalagem do papaia para exportação, a maturação dos frutos é classificada manualmente, baseando-se na coloração dos frutos. Este procedimento, por ser subjetivo, está sujeito a diferentes interpretações, uma vez que depende do treinamento do classificador e é muito afetado pela fadiga do mesmo, podendo resultar em desuniformidade do estádio de maturação dos frutos na caixa e entre caixas de diferentes classificadores. Também o grande número de frutos classificados na indústria requer intensa utilização de mão-de-obra, aumentando, como conseqüência, o custo do produto.

A utilização de parâmetros físicos para classificação da cor dos estádios de maturação do papaia abre a possibilidade da automatização do procedimento pela utilização de equipamentos com sensores óticos, que poderia aumentar a eficiência e eficácia da seleção.

Este trabalho teve como objetivo definir valores médios de $L, a$ e $b$ e refletância da casca do papaia 'Golden' em função dos estádios de maturação.

Neste experimento, foram utilizados papaias ‘Golden' tipo exportação, procedentes de uma lavoura e colhidos no mesmo dia, no município de Linhares (ES). A região de produção apresenta temperaturas máximas entre $30^{\circ} \mathrm{C}$ e $32^{\circ} \mathrm{C}$, mínimas entre $15^{\circ} \mathrm{C}$ e $18^{\circ} \mathrm{C}$ e precipitação anual de $1200 \mathrm{~mm}$. Os frutos foram

1 (Trabalho 165/2001). Recebido: 15/10/2001. Aceito para publicação: 02/05/2002.

2 Eng ${ }^{0}$ Agr $^{0}$ Mestre em Produção Vegetal pela UENF, Laboratório de Tecnologia de Alimentos da UENF-CCTA. Av. Alberto Lamego, 2000, Campos dos Goytacazes, RJ, CEP - 28015-620, tel: (024) 726-3746, mayron@uenf.br.

3 Prof. Ph.D. do Laboratório de Tecnologia de Alimentos da UENF-CCTA. Av. Alberto Lamego, 2000, Campos dos Goytacazes, RJ, CEP - 28015620, tel: (024) 726-3746, vianni@uenf.br.

4 Eng ${ }^{\underline{0}}$ Agr ${ }^{-}$Mestre em Produção Vegetal pela UENF, Laboratório de Tecnologia de Alimentos da UENF-CCTA. Av. Alberto Lamego, 2000, Campos dos Goytacazes, RJ, CEP - 28015-620, tel: (024) 726-3746, gewson@ bol.com.br.

5 Bolsista de iniciação científica do Laboratório de Tecnologia de Alimentos da UENF-CCTA. Av. Alberto Lamego, 2000, Campos dos Goytacazes, RJ, CEP - 28015-620, tel: (024) 726-3746, thiagoaraujo@ censa.com.br. 
submetidos ao tratamento térmico e fitossanitário utilizados pelo exportador, seguindo as normas do Ministério da Agricultura (Ritzinger \& Souza, 2000). As leituras de cor, com o emprego do colorímetro, foram realizadas no galpão de embalagem.

Foram avaliados frutos do tipo 9, que pesavam entre 390 e 439 gramas (Marin et al., 1995). Os estádios de maturação utilizados foram 2; 3; 4 e 5, segundo a classificação normalizada pelo acordo bilateral de 1999 entre a Secretaria de Defesa Agropecuária (SDA) do Ministério da Agricultura e Abastecimento do Brasil e o Departamento Norte-Americano de Agricultura (USDA), Serviço de Inspeção de Saúde Animal e Vegetal (APHIS), que classifica estes estádios de maturação do papaia (Tabela 1). Os frutos no estádio 2 de maturação são os mais utilizados para exportação, e, no estádio 5, são considerados aptos para o consumo.

Foram utilizados 100 frutos em cada estádio de maturação e, em cada um dos frutos, foram realizadas 4 leituras eqüidistantes e aleatórias na região equatorial. O delineamento experimental utilizado foi o inteiramente casualizado, com 100 repetições, sendo cada parcela composta pela média das leituras de cada fruto.

Com o colorímetro de Hunter modelo MiniScan XEplus
(HunterLab, USA), foram determinados os parâmetros $L, a, b$ e refletância da casca entre 400 e $700 \mathrm{~nm} ; L$ refere-se à luminosidade da amostra, sendo que valores próximos a 100 representam o branco e próximos a 0 o preto, valores de $a$ positivos tendem ao vermelho e negativos tendem ao verde. Valores de $b$ positivos indicam tendência ao amarelo e negativos para o azul.

Todos os parâmetros foram significativamente influenciados pelo estádio de maturação (Tabela 2) com médias estatisticamente diferentes ao nível de 5\% (Tabela 3). Podem-se notar acréscimos nos valores de todos os parâmetros em função do estádio de maturação, o que indica aumento da contribuição das cores primárias negro, vermelho e amarelo durante o período de amadurecimento.

O espectro médio de refletância da casca dos frutos entre 400 e 700 nm, mostrado na Figura 1, reforça o que foi observado para os parâmetros $a$ e $b$, pois entre 520 e $700 \mathrm{~nm}$, que compreende verde, amarelo, alaranjado e vermelho, existe a maior amplitude de refletância entre os estádios de maturação, notadamente para a faixa entre amarelo e alaranjado.

Conclui-se que os valores de $L, a$ e $b$ e refletância da casca dos frutos na região do amarelo (580 - 595nm) e alaranjado

TABELA 1 - Classificação do estádio de maturação do papaia para exportação.

\begin{tabular}{|c|c|}
\hline $\begin{array}{c}\text { Estádio de } \\
\text { maturação }\end{array}$ & Descrição \\
\hline 2 & $1 / 4$ madura. Fruta com até $25 \%$ da superfície da casca amarela, rodeada de verde-claro. \\
\hline 3 & $\begin{array}{r}1 / 2 \text { madura. Fruta com até } 50 \% \text { da superfície da casca amarela, com áreas próximas em verde- } \\
\text { claro. }\end{array}$ \\
\hline 4 & $\begin{array}{r}\text { Madura. Fruta com } 76-100 \% \text { da superfície da casca amarela. Somente a extremidade do } \\
\text { pedúnculo é verde, a partir da área de constrição. }\end{array}$ \\
\hline 5 & \\
\hline
\end{tabular}

Ritzinger \& Souza, 2000

TABELA 2 - Resumo da análise de variância das características determinantes da cor da casca dos frutos de papaia em função do estádio de maturação.

\begin{tabular}{|l|l|l|l|}
\hline & G.L. & $L$ & $a$ \\
\hline Quadrado m é dio do e stádio & 3 & 1712,5 & 2179,8 \\
\hline Quadrado m édio do erro & 396 & 4,9 & 3,6 \\
\hline$F$ & $<0,001$ & $<0,001,96$ & $<0,001$ \\
\hline
\end{tabular}

TABELA 3 - Valores médios de $L$, a e $b$ entre os estádios de maturação.

\begin{tabular}{c|l|l|c}
\hline Estádio de Maturação & \multicolumn{1}{|c}{$L$} & \multicolumn{1}{|c}{$a$} & $b$ \\
\hline 2 & $54,547( \pm 2,607)^{a} \mathrm{~d}$ & $-4,656( \pm 1,754) \mathrm{d}$ & $24,822( \pm 1,407) \mathrm{d}$ \\
3 & $58,004( \pm 2,194) \mathrm{c}$ & $-1,315( \pm 1,862) \mathrm{c}$ & $27,648( \pm 1,612) \mathrm{c}$ \\
4 & $61,089( \pm 1,997) \mathrm{b}$ & $2,037( \pm 2,011) \mathrm{b}$ & $29,841( \pm 1,335) \mathrm{b}$ \\
5 & $64,200( \pm 2,037) \mathrm{a}$ & $6,258( \pm 1,903) \mathrm{a}$ & $32,190( \pm 1,218) \mathrm{a}$ \\
\hline
\end{tabular}

a Desvio-padrão.

Valores seguidos de letras diferentes na vertical diferem significativamente entre si, pelo teste de Tuckey, ao nível de 5\%. 


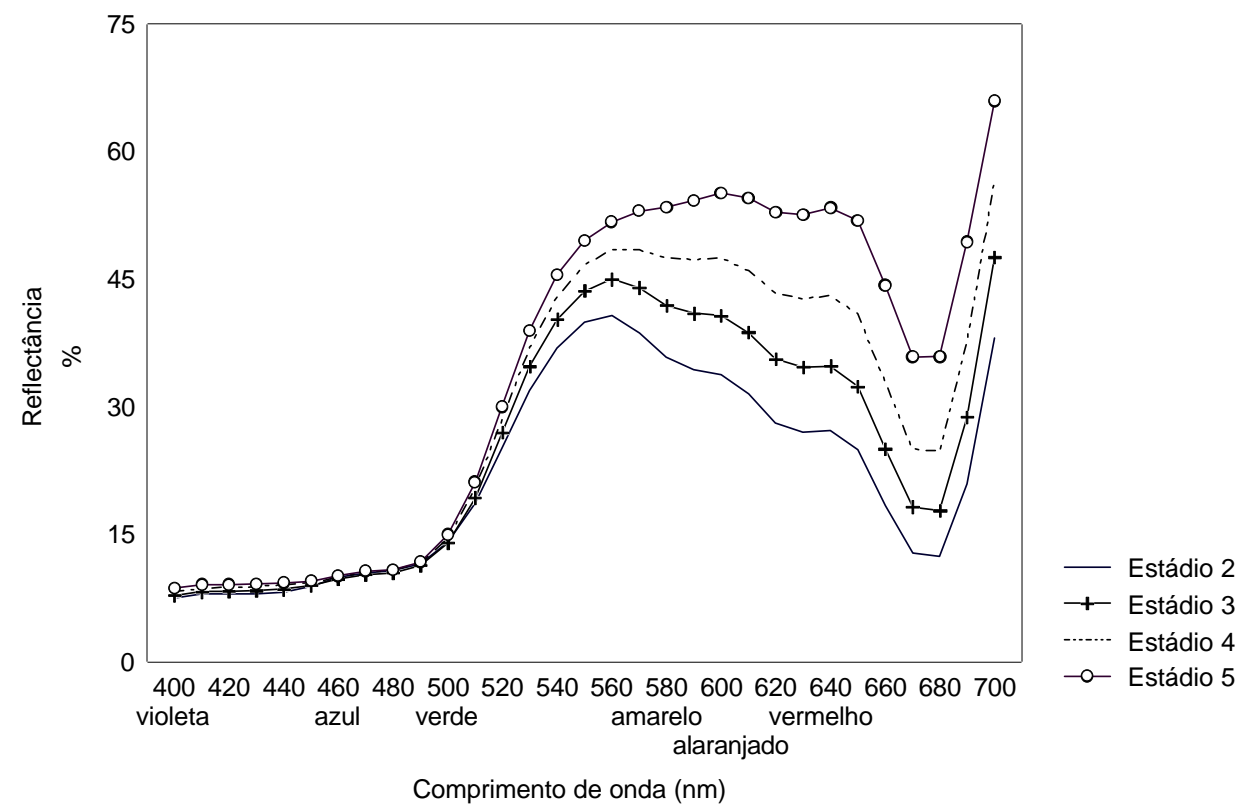

FIGURA 1 - Espectro médio de refletância da casca do papaia nos estádios de maturação.

(595 - 620nm) podem ser utilizados para definir diferentes estádios de maturação do papaia 'Golden', nos estádios de maturação 2; 3; 4 e 5. Portanto, instrumentos e equipamentos destinados a automatizar um processo de seleção mecânica do papaia 'Golden' deveriam considerar estes parâmetros.

\section{REFERÊNCIAS BIBLIOGRÁFICAS}

KAYS, S. J. Postharvest physiology of perishable plant products. New York: AVI, 1991.532p.

MARIN, S. L. D.; GOMES, J. A.; SALGADO, J. S.; MARTINS, D.
S.; FULLIN, E. A. Recomendações para a cultura do mamoeiro dos grupos Solo e Formosa no Estado do Espírito Santo. 4. ed Vitória: EMCAPA 1995.57p.(Circular Técnica)

RITZINGER, CECÍLIA HELENA SILVINOPRATA; SOUZA, JOSÉ DA SILVA (org.) Mamão: Fitossanidade. Cruz das Almas: EMBRAPA, 2000.91p.

VIEIRA, G.; VIÉGAS, P. R. A.; NEVES, J. C. L.; AGNES, E. L.; OLIVEIRA, F. A. M. B. Influência da cultivar e do estádio de maturação em algumas características de frutos de mamão durante a pós-colheita. Revista Brasileira de Fruticultura, Jaboticabal, n. 2, p. 244-247, 2000. 